\title{
Response suppression and facilitation by aversive stimuli following septal lesions in rats: A review and model*
}

\author{
ANTHONY DICKINSON \\ Laboratory of Experimental Psychology, University of Sussex, Sussex, England BN1 $9 Q G$
}

\begin{abstract}
Evidence concerning the effects of septal damage on the performance of rats in tasks involving shock and frustrative nonreward is reviewed. It is argued that the behavior of rats with septal lesions cannot be understood in terms of either a change in the functional intensity of aversive stimuli or the ability to register contingencies between such stimuli and responding. Rather, the lesion appears to decrease the suppressive property of aversive stimuli while augmenting their facilitative or drive-enhancing property. On the basis of the evidence, a model of the processing of aversive stimuli is proposed. The model assumes that aversive stimuli are processed by two relatively independent systems: a response suppression system associated with septal functioning and a response facilitation system associated with amygdala functioning. While the facilitation mechanism is activated by stimuli of both positive and negative affective value, the suppression system is sensitive to only aversive events. Further, it is suggested that an additional septal mechanism, sensitive to both positive and negative stimuli, exerts inhibitory control over the facilitation system.
\end{abstract}

The mechanisms involved in processing the environmental contingencies resulting in response reduction are as central to the understanding of general adaptive behavior as the mechanisms by which responding is engendered. The two most common contingencies for decreasing response output are extinction and punishment. In spite of considerable study and use, there is, as yet, no general consensus about the nature of the mechanisms mediating the effectiveness of these contingencies.

Faced with the problem of instrumental extinction, learning theorists have proposed basically two types of explanation. The first assumes that the omission of reward does not bring into play any new behavioral processes and that the response decrement can be understood primarily in terms of the removal of response maintaining processes and stimuli associated with reward. By contrast, other authors have argued that extinction involves some additional inhibitory mechanism (e.g., Spence, 1936). A similar division is discernible in discussions of the effectiveness of punishment (cf. Church, 1963). The capacity of aversive stimuli to suppress responding has been regarded by some writers as secondary to other properties of these stimuli, such as their ability to maintain avoidance behavior (e.g., Mowrer, 1947; Dinsmoor, 1954; Solomon, 1964). Against this view, it has been argued that a specific suppression or response-reduction mechanism is required to understand the effectiveness of

\footnotetext{
*Preparation of this paper was supported by a grant from the U. K. Science R esearch Council. I should like to thank N. J. Mackintosh and E. M. Macphail for reading an earlier draft of the paper. Requests for reprints should be sent to Anthony Dickinson, Laboratory of Experimental Psychology, University of Sussex, Sussex, England BN1 9QG.
}

punishment (e.g., Estes, 1969; Rachlin \& Herrnstein, 1969; Dunham, 1971).

Over the last decade or so, a number of ablation studies have shown that animals with lesions of certain subcortical structures exhibit abnormally, persistent responding in extinction and under punishment. The significant feature of these dysfunctions is that they appear to be unaccompanied by any gross distortion of response acquisition and maintenance. On the most general level of analysis, the selectivity of the deficit pattern supports the idea that punishment and extinction involve mechanisms specific to these contingencies. Furthermore, if the "Functioning" of brain-injured organisms is ... likely to reveal the 'natural fracture lines' of behavior ... [Thomas, Hostetter, \& Barker, 1968]," this selectivity suggests that a detailed behavioral analysis of the dysfunctions might contribute to our understanding of normal adjustment to extinction and punishment. The present paper attempts to analyze the behavioral effects of large septal lesions in the rat from this point of view. Evidence from studies of septal damage in other species will be included primarily where the relevant data are not available for the rat. Furthermore, questions concerning the anatomical and neurophysiological representations of the functional systems under consideration are treated as of secondary importance, and emphasis is to be placed upon giving an adequate behavioral characterization of the dysfunctions associated with septal damage.

\section{SEPTAL LESIONS AND RESPONSE PERSISTENCE}

The number of studies of the behavioral effects of septal damage has grown considerably in recent years. 
Contemporary reviews by Fried (1973), Lubar and Numan (1973), and Caplan (1973) illustrate the wide range of effects investigated. However, many of these effects can be regarded as expressions of common dysfunctions. In the next two sections, I shall argue that a number of the behavioral changes can be regarded as falling into two similar classes: response persistence under shock and response persistence under nonreward. The possibility that these dysfunctions are just a manifestation of a general learning or performance deficit will then be considered.

\section{Persistence Under Shock}

Rats with septal damage emit responses punished by a shock at a higher frequency than intact animals in a wide variety of situations. This persistence has been found when both appetitive instrumental (e.g., Schwartzbaum \& Spieth, 1964; Harvey, Lints, Jacobson, \& Hunt, 1965) and consummatory responses (e.g., Kaada, Rasmussen, \& Kviem, 1962) are punished. In addition, septal lesions have been reported to enhance the emission of spontaneous, nonreinforced responses under punishment (Winocur \& Mills, 1969; Thomas, 1972). These changes appear to represent real differences in the direct modification of response tendencies by punishment. Shock persistence is present when the baseline rate of the punished response is the same for control and operated animals (Kasper-Pandi, Schoel, \& Zysman, 1969; Beatty, Beatty, O’Briant, Gregoire, \& Dahl, 1973) and when the motivational levels of the groups are equated by independent manipulations (Lubar, Schaeffer, \& Wells, 1969; Beatty et al, 1973). Moreover, it appears unlikely that the persistence is a consequence of any simple change in competing responses, such as freezing. Ursin, Linck, and McCleary (1969) employed a situation in which the avoidance tendency elicited in normal animals by punishment of a previously rewarded response was an active response. Even so, the septal damage enhanced the emission of the punished response.

Another reliable finding associated with septal damage is facilitation of performance in a two-way active-avoidance task (e.g., King, 1958; Krieckhaus, Simmons, Thomas, \& Kenyon, 1964; Schwartzbaum, Green, Beatty, \& Thompson, 1967). The peculiar feature of this task is that a successful avoidance response requires the animal to return to a chamber where it has very probably been shocked on previous trials. This requirement gives a considerable role to a passive avoidance or punishment process in the performance of normal animals. It is well known that acquisition of the two-way response is inversely related to shock level for intact rats (Moyer \& Korn, 1964; Theios, Lynch, \& Lowe, 1966; McAllister, McAllister, \& Douglas, 1971). Freedman, Hennessy, and Groner (1974) have shown that this inverse relationship is largely due to the effect of shock level on the passive avoidance or punishment component. By varying the shock level associated with each compartment of the shuttlebox independently, they found that avoidance performance was an inverse function of the level associated with the chamber into which the animal was required to move. Responding was relatively independent of the level associated with the chamber from which the animal was required to flee. From this analysis, it can be argued that any treatment, such as septal damage, which decreases the effectiveness of punishment should enhance performance. In fact, Garber and Simmons (1968) have reported that when different shock levels are associated with the two chambers, septal lesions enhance performance only when the animal is required to avoid or escape into the higher shock compartment. Thus, the enhanced two-way avoidance performance can be regarded as an indirect manifestation of the effect of the lesion on response persistence under punishment.

Finally it should be noted that all the above studies used shock as the punishing stimulus. The generality of the deficit when other aversive stimuli are used has been questioned. For instance, Gittleson, Donovick, and Burright (1969) and Frank and Beatty (1974) observed enhanced suppression following the lesion when quinine and iced water, respectively, were used as the aversive stimulus.

\section{Persistence Under Nonreward}

Persistent responding following the withdrawal of reward and similar operations has been reported in a wide variety of situations for septal-lesion animals. Some enhanced responding has been found during simple extinction (Schwartzbaum, Kellicutt, Spieth, \& Thompson, 1964; Raphelson, Isaacson, \& Douglas, 1966; Gray, Quintao, \& Araujo-Silva, 1972; Henke, 1974), although the magnitude of the effect appears to be considerably greater in the nonrewarded stimulus of a successive go/no-go discrimination. Dickinson (1973), using a free-operant procedure, reported that septal damage not only decreased the rate at which responding declined in the nonrewarded stimulus but also resulted in a higher asymptotic rate in that stimulus. Comparable effects have also been found in discrete trial go/no-go discriminations by Koppell and Sodetz (1972).

A number of other lesion-induced effects can be regarded as examples of nonreward persistence. Schwartzbaum and Donovick (1968) found that, following the lesion, rats required more trials to reverse a simultaneous position discrimination, and that this deficit was largely due to persistent responding to the stimulus reinforced during acquisition. The effect does not appear to be limited to position-discrimination reversals. Deficits have been found for rats in the reversal of a simultaneous kinaesthetically cued discrimination (Gittleson \& Donovick, 1968) and for cats in the reversal of a simultaneous object discrimination (Zucker, 1965). Schwartzbaum and Donovick (1968) failed to find a significant effect of the lesion on the reversal of a 
brightness discrimination; however, they do suggest that the basic difficulty of the reversal for intact animals might have masked any effect of the lesion. The nonsignificant difference between the group scores was in the direction of a deficit.

A third class of behavioral change which can be regarded as an example of nonreward persistence is revealed by the use of certain free-operant schedules. These are schedules which normally maintain low response rates by omitting reinforcement for certain classes of response. Rats with septal damage emit more nonreinforced responses on both fixed-interval schedules (e.g., Ellen \& Powell, 1962) and DRL schedules (e.g., Ellen, Wilson, \& Powell, 1964) if the full valued DRL schedule is introduced relatively rapidly after continuous reinforcement (Caplan \& Stamm, 1967). This persistence can be regarded as another example of the failure of the omission of an expected reward to suppress responding following septal damage.

\section{Selectivity of Dysfunctions}

If one wishes to argue that the study of animals with septal lesions may be of value in understanding mechanisms peculiar to normal response suppression, it is necessary to show that the persistence is not just a symptom of a general learning deficit. There is good evidence that septal damage has little effect on learning when the task does not explicitly require response decrements under aversive stimulation or nonreward. If a strong opposing response tendency has not been established and if the animal has the opportunity to make an alternative, active, reinforced response on each trial or occasion, little behavioral disturbance results. Animals with septal lesions show normal acquisition functions in a variety of simultaneous discriminations (e.g., Schwartzbaum \& Donovick, 1968; Schnelle, Walker, \& Hurwitz, 1971) and, for mice, in response-sequencing tasks (Carlson \& Cole, 1970). Dickinson (1973) found that if a successive go/no-go discrimination, in which septal damage had been shown to produce persistence, was converted into a successive go/go discrimination with the same stimuli and reinforcement schedules, operated animals performed at least as efficiently as controls. Perhaps the strongest evidence that septal damage does not result in any general learning deficit comes from the similarity of acquisition functions of septal and intact rats in a variety of complex mazes (Thomas, Moore, Harvey, \& Hunt, 1959; Ain, Lubar, Moon, \& Kulig, 1969) although it should be noted that a deficit in a complex reasoning task has been reported (Stahl \& Ellen, 1973). Finally in the rat, at least, septal lesions produce little detectable change in a range of species-specific behavior (Slotnick, 1967; Lubar, Herrman, Moore, \& Shouse, 1973).

\section{RESPONSE-STIMULUS CONTIGUITY AND AVERSIVENESS}

One of the most widely quoted explanations of the response persistence under shock and nonreward is that septal damage disrupts a mechanism mediating the general inhibition of somatic responses (Gerbrant, 1965; McCleary, 1966). The implication is that the enhanced persistence should be manifest in all situations where a relatively strong response tendency has been established. However, recent evidence questions the generality of the deficit. Using a successive go/no-go discrimination, Koppell and Sodetz (1972) found that enhanced persistence only occurs in a stimulus associated with extinction if responding is maintained in the other stimulus by positive reinforcement rather than by shock avodance and escape. The withdrawal of a positive reinforcer appears to be necessary for septal damage to increase persistence of an instrumental response in extinction. 1 This selectivity suggests that an account of the septal dysfunction should focus upon the type of event contingent upon responding in response suppression situations. For many years, frustration theorists (Amsel, 1958, 1962) have maintained that the omission of an expected reward is an aversive event with many properties in common with other aversive events such as shock. Wagner (1969) has documented the similarity between frustrative nonreward and shock. Within this framework, shock and nonreward persistence can be seen as the products of a common disturbance, namely, the dysfunction of a mechanism which produces response suppression when an aversive event is programmed to follow the emission of a response. Such an analysis immediately suggests two processes on which the lesion may act. In order to suppress responding, a normal animal must first associate emission of the response with the stimuli that follow it whether these are externally generated, as in the case of shock, or internally generated, as in the case of frustration. Secondly, the animal must register these stimuli as aversive. A lesion-induced disruption of either of these two processes could lead to response persistence.

\section{Sensitivity to Response-Stimulus Contiguity}

Ellen and his colleagues (Ellen \& Butter, 1969; Ellen $\&$ Kelnhoffer, 1971) have suggested that septal damage interferes with the processing of response-associated cues. Such a deficit might lead to difficulty in associating the emission of a response with the presentation of a contingent stimulus, such as shock. The origin of this suggestion was an experiment (Ellen \& Butter, 1969) which demonstrated that programming an external stimulus change when the required interresponse time had elapsed on a DRL schedule enabled lesioned rats to perform as efficiently as controls. Without this "clock" stimulus, operated 
animals had a greater tendency to emit interresponse times shorter than the required length. The general DRL deficit and the beneficial effect of the "clock" stimulus can be understood if septal lesions prevent the animal from using response-generated cues effectively for timing. In line with this idea, Ellen and Kelnhoffer (1971) subsequently reported a septal deficit in a task which explicitly required the animal to use the amount of emitted behavior as a discriminative stimulus in a response chain (but see Van Hoesen, MacDougall, \& Mitchell, 1972, for the opposite finding).

It is well known that normal animals are sensitive to the contiguity between the response and the aversive stimulus programmed by punishment procedures. A number of studies (e.g., Camp, Raymond, \& Church, 1967) have shown that shock which occurs immediately following a response produces more suppression than the comparable noncontingent or delayed presentation. The difference between the degree of suppression maintained by contingent and noncontingent shock can be regarded as a measure of the ability to associate response-generated cues with an aversive stimulus. If the response persistence following septal damage is primarily due to a deficit in this ability, the difference between the suppressive effects of contingent and noncontingent shock should be reduced by the lesion. To investigate this possibility, Dickinson (1974) compared the suppression of a free-operant food-reinforced response by contingent and noncontingent shock in lesioned and intact rats. Although septal damage produced a higher response rate under both conditions, there was no interaction between the effect of the lesion and response contingency; the difference between the rates in the contingent and noncontingent conditions was the same for both the lesion and control groups. The effect of septal damage on response suppression by shock appears to be general and not specifically dependent upon establishing a relationship between responding and shock presentation.

\section{Decrement in Aversiveness}

A second explanation of the persistence is that the lesion attenuates the effective aversiveness of normally noxious stimuli. Gray (1970) and Lubar and Numan (1973) have made similar suggestions. The main implication of such a hypothesis is that the behavior of brain-damaged rats should reflect this attenuation in other situations which, at least on a superficial level of analysis, do not involve response suppression. Studies of performance following septal lesions are available for three such measures: avoidance learning, escape learning, and unconditional reactions to footshock.

Avoidance Learning. It was suggested above that two-way active avoidance, by requiring the animal to return to a situation where it has probably been shocked, involves a significant passive avoidance or punishment component. Consequently, performance changes in this situation following the lesion or variation in shock intensity cannot be taken as reflecting changes in the aversive motivation underlying avoidance unconfounded by variations in the effectiveness of a punishment or passive avoidance contingency. Three other avoidance situations remain in which the effects of septal damage have been tested: one-way avoidance, discrete-trial leverpress avoidance, and free-operant or Sidman avoidance. Ideally, if septal damage decreases the aversiveness of the shock, reductions of US intensity should produce comparable behavioral changes in normal animals. However, in all three cases, the validity of the comparison is far from clear.

At first sight, reports of a decrement in the acquisition of one-way avoidance seem to agree with the hypothesis (Vanderwolf, 1964; Kenyon \& Krieckhaus, 1965; McNew \& Thompson, 1966; Duncan \& Duncan, 1971). However, McCleary (1966) has suggested that the deficit in this type of situation might be due to the increased àversiveness of intertrial handling for the lesioned animals. The effects of septal damage on the performance of rats in one-way situations when nonhandling procedures are used is unclear. Dalby (1970) and Hamilton (1972) found no decrement as a result of the lesion, while the outcome of an experiment by Deagle and Lubar (1971) suggests that the strain of the rat might be important. Although septal damage in hooded rats had no effect on one-way avoidance, albino rats exhibited a marked deficit following the lesion. However, certain features of the results suggest that this deficit cannot be taken as strong evidence for reduced aversiveness. Both the hooded and albino rats showed the typical enhancement of two-way avoidance. In the albino groups, but not the hooded, this enhancement of two-way avoidance and deficit in one-way avoidance were so marked that the median trials to criterion in the two-way task was considerably lower than that in the one-way task. It is normally found that oneway avoidance is acquired significantly faster than two-way in intact rats at all shock levels (cf. Theios et al, 1966). Following the discussion of two-way avoidance in a preceding section, this procedure can be regarded as the same as the one-way except for the addition of a passive-avoidance or punishment contingency. If septal damage and shock reduction facilitate two-way performance by reducing the effectiveness of the passive-avoidance component, these two manipulations should make two- and one-way performance converge but never cross over. Such a crossover is suggested by the result of the Deagle and Lubar (1971) experiment. Finally, it should be noted that the performance of normal rats in one-way avoidance is fairly insensitive to variations in the aversiveness of the shock by manipulations of intensity (Theios et al, 1966; Freedman et al, 1974).

Thomas and Van Atta (1972) found that discrete-trial leverpress avoidance was improved by septal damage. However, the significance of this change for the 
reduced-aversiveness hypothesis is also ambiguous, for variations in shock intensity appear to have differential effects on the acquisition and maintenance of leverpress avoidance. While a number of studies (e.g., Bolles \& Warren, 1965; D'Amato \& Fazzaro, 1966) have reported an inverse relationship between acquisition rate and intensity, D'Amato, Fazzaro, and Etkin (1967) found that if all rats were allowed to acquire the response under optimum conditions, subsequent performance improved with increases in shock intensity. Inspection of the Thomas and Van Atta (1972) data suggests that the lesion effect was mainly on initial acquisition. However, it might not be appropriate to equate such a change with a reduction in the functional aversiveness of the shock. D'Amato and his colleagues (D'Amato \& Fazzaro, 1966; D'Amato et al, 1967) have explained the inverse relationship between shock intensity and acquisition in terms of the degree of conditioned response suppression produced by the shock. As we know that septal damage attenuates response suppression under shock, the enhanced leverpress acquisition may be due to the same factors as operate in the two-way avoidance situation, namely reduction in the competition between the avoidance response and alternative behavior engendered by the shock.

The third paradigm, free-operant avoidance, has produced results which are clearly not amenable to a simple reduced-aversiveness hypothesis. Typically, a reduction of shock intensity produces a decrement in response rate and an increase in shock rate in intact rats using a leverpress response (Powell, 1970; Riess, 1970; Riess \& Ferrar, 1972). While septal damage also decreases response rate, this reduction is not accompanied by an increment in shock rate; the shock rate either remains unaltered (Sodetz, 1970, 1972) or is actually reduced (Morgan \& Mitchell, 1969; Duncan \& Duncan, 1971).

Escape Learning. The effects of septal damage on escape learning and performance have received far less study than in the case of avoidance. Gotsick, Osborne, Allen, and Hines (1971) investigated escape from shock using a leverpress response. Although brain-damaged and normal rats acquired the response at the same rate, intact animals consistently maintained lower escape latencies. However, the authors argued against interpreting this result as evidence for a lesion-induced decrement in shock aversiveness. The latency difference appeared to arise from the fact that control animals were more likely to remain near the lever during the intertrial interval and therefore be in a better position to respond rapidly with shock onset. Further caution is suggested by Brown and Remley's (1971) finding that septal damage actually decreased the latency of escape from shock in a shuttlebox.

Using an escape procedure, changes in the aversiveness of frustrative nonreward can also be studied. Rilling, Askew, Ahlskog, and Kramer (1969) showed that animals will acquire and maintain a response which terminates the stimulus conditions associated with the nonrewarded component of a go/no-go discrimination and institutes a time-out period never previously associated with reinforcement. Using a similar procedure, Dickinson (1972a) found that septal damage actually augments the level of escape from frustrative nonreward; a finding at variance with the reduced-aversiveness hypothesis.

Unconditioned reactions. Although septal lesions do not appear to alter the detection threshold for footshock (Blanchard \& Fial, 1968; Lints \& Harvey, 1969; Lubar, Brener, Deagle, Numan, \& Clemens, 1970), there is a marked increase in supra-threshold reactivity. This is reflected by an increase in postshock activity (Lints \& Harvey, 1969; Lubar et al, 1970) and shock-elicited fighting (e.g., Wetzel, Conner, \& Levine, 1967; Ahnad \& Harvey, 1968; Blanchard \& Blanchard, 1968) and a decrease in the jump threshold (Lints \& Harvey, 1969; Eichelman, 1971; Carey, 1972; Miczek, Kelsey, \& Grossman, 1972) and the degree of postshock freezing (Blanchard \& Fial, 1968).

It is clear from this survey that the effects of septal damage on aversively motivated behavior cannot simply be explained in terms of a shift in the effective aversiveness or functional intensity of the noxious event. The pattern of dysfunction is too complex. Although response-suppression and two-way active-avoidance changes can be characterized in terms of decreased aversiveness, the effects of the lesion on escape and unconditional reactions in fact suggest an increment in functional intensity. Other lesion-induced dysfunctions, such as those exhibited in free-operant avoidance, do not fit any simple modulation of aversiveness.

\section{FACILITATING EFFECTS OF AVERSIVE STIMULI}

An alternative to assuming that the lesion changes responsivity to aversive events along some unitary dimension, such as intensity, is to argue for a qualitative change. Two main properties have often been attributed to aversive stimuli. As well as having suppressive effects, they can also facilitate responding by contributing to the general arousal or drive level of the animal (cf. Brown, Kalish, \& Farber, 1951). The studies considered in the previous sections suggest that if aversiveness is measured by a technique involving response suppression, either directly (e.g., punishment) or indirectly (e.g., two-way active avoidance), the lesion produces an apparent decrease in aversiveness. On the other hand, if the scheduling of the aversive stimulus normally maintains an active response without involving an approach-avoidance or an avoidance-avoidance conflict, performance is unchanged or even increased. Perhaps septal damage selectively decreases the suppressive property of noxious stimuli, while leaving the energizing effects relatively unaffected. 
The performance of rats with septal damage has been measured in a variety of situations assumed to be sensitive to the energizing or facilitative effects of aversive events. These situations have employed both conditioned and unconditioned aversive stimuli based on shock and frustrative nonreward.

\section{Facilitating Effects of Shock}

Conditioned Acceleration. The behavioral response often taken as reflecting the purest measure of the motivational property of aversive stimuli is the acceleration in free-operant avoidance which occurs when a CS, previously paired with shock in a different Pavlovian situation, is presented (Rescorla \& Solomon, 1967). The degree of acceleration appears to be monotonically related to the shock magnitude employed in the Pavlovian stage (e.g., Martin \& Riess, 1969; Riess \& Farrar, 1973), given that the shock intensity is not too high (Scobie, 1972). Using this procedure, Dickinson and Morris (1974) found that septal damage did not alter the magnitude or pattern of acceleration when a tone previously paired with shock was presented while the rats were performing a free-operant wheel-turn response.

Punishment-Reward Correlations. A number of studies (e.g., Williams \& Barry, 1966; Murray \& Nevin, 1967; Appel, 1968) have shown that the change in response output with the introduction of response-contingent shock depends upon which responses are punished. Murray and Nevin (1967) varied the relationship between shock and reward on a schedule in which responding was both intermittently punished and reinforced. They found that if a positive correlation is established between shock of an appropriate level and reward, by punishing only reinforced responses, an increase in response rate above the baseline level can occur. This is true even though punishing only nonreinforced responses with the same shock level and frequency (negative correlation) leads to considerable response suppression. It is as though the negative correlation optimises the suppressive effects of the shock and the positive correlation, the activating effects. On this assumption, Dickinson (1974) argued that, if septal damage selectively attenuates the suppressive effects of shock without decreasing the invigorating property, operated rats should show response persistence under the negative correlation while responding at least as rapidly as intact animals under the positive correlation. In fact, the lesion actually appeared to potentiate the activating effects of the shock; the introduction of positively correlated shock increased the response rate of the lesion group to a level that was not only above their baseline rate but also above the rate maintained by the control group. In the negatively correlated condition, the experimental rats showed the normal response persistence found in punishment situations.

\section{Facilitating Effects of Frustrative Nonreward}

Frustration Effect. If an animal is intermittently rewarded in the first goalbox of a double runway (cf. Amsel \& Roussel, 1952), it is typically found that the speed in the second alley is faster following nonreward than following reward. This difference is usually ascribed to the energizing effects of frustration elicited by the omission of the expected reward. The magnitude of this frustration effect is unaffected by septal damage in both the conventional double runway (Mabry \& Peeler, 1972) and in a free-operant analogue (Dickinson, 1972a). In fact, Schwartzbaum and Kreinick (1974) have recently reported that septal damage actually heightens electrophysiological reactivity to reward omission.

Partial Reinforcement Acquisition Effect. Partial reinforcement has been found to result in faster performance in certain segments of an alleyway than continuous reinforcement (e.g., Goodrich, 1959). This elevation has also been attributed to the energizing effects of frustrative nonreward. Unfortunately, the only studies directly comparing the effect of septal damage on performance under partial and continuous reward in a runway failed to find an acquisition effect in intact animals (Gray, Quintao, \& Araujo-Silva, 1972; Henke, 1974). However, free-operant schedules obviously involve partial reinforcement, and performance on such schedules could be reasonably expected to be sensitive to any energizing effects of nonreward. Generally, septal damage has been found to augment responding on a variety of free-operant schedules. Hothersall, Johnson, and Collen (1970) reported higher rates for brain-damaged rats than for controls on fixed-ratio schedules, and the magnitude of the lesion effect increased with the size of the ratio. Comparable increments have also been found for variable(Dickinson, 1972b, 1973, 1974) and fixed-interval schedules (Ellen \& Powell, 1962). These differences tend to emerge with training (Dickinson, 1972b, 1973), suggesting that the rate increment does not simply reflect a change in the appetitive motivational state underlying the response. In addition, all the above studies used food as the reinforcement, and there is good evidence that septal lesions neither alter free-food intake (Carey, 1969; Besch \& Van Dyne, 1969; Donovick, Burright, \& Gittleson, 1969; Kasper-Pandi et al, 1969; Lorens \& Kondo, 1969; Wishart \& Mogenson, 1970) nor free-operant responding when the schedule does not involve response suppression and only limited exposure is given (Carey, 1969).

Behavioral Contrast. In a typical free-operant successive go/no-go discrimination, an animal is reinforced during two successively presented stimuli during a baseline period until response rates stabilize. Responding is then extinguished in one of the stimuli. It is often found that, as responding declines in the nonrewarded stimulus, the rate in the other stimulus 
rises above the baseline level (Freeman, 1971). This phenomenon has been referred to as behavioral contrast, and a number of authors have attributed the increment to the activating effects of frustration elicited in the nonrewarded stimulus upon responding in the rewarded stimulus (Bloomfield, 1967; Amsel, 1971). Dickinson (1973) investigated the effects of septal damage on the development of behavioral contrast. Figure 1 illustrates the average number of responses emitted by septal and control rats during the rewarded stimulus ( $\mathrm{S}+$ ) as a function of the number of nonrewarded stimuli (S-)

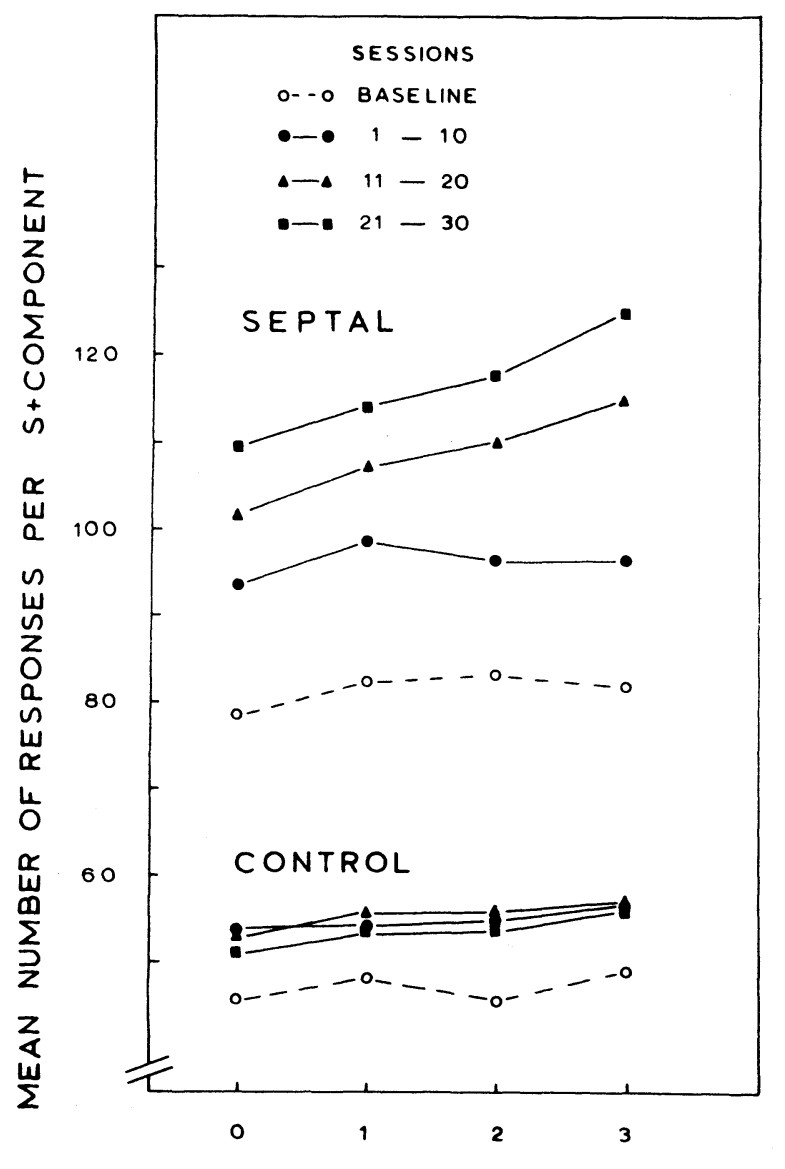

NUMBER OF PRECEDING

\section{S-COMPONENTS}

Fig. 1. Mean number of leverpress responses emitted in the positive component (S+) of a successive go/no-go discrimination as a function of the number of proceeding negative components (S-) for a septal-lesion and control group. The components were of 2-min duration and randomly intermixed. The functions are shown separately for the last five sessions of baseline training and for successive 10-session blocks of discrimination training. During the baseline, responding was reinforced with food on a VI 45-sec schedule in both components. During discrimination training, responding in $\mathbf{S}$ - components was extinguished while the schedule of reinforcement in $\mathrm{S}+$ components remained VI 45-sec. immediately preceding the $\mathrm{S}+$. The response number is shown separately for the last 5 baseline sessions and for successive 10-session blocks of discrimination training. In this experiment, control animals showed little evidence of contrast; their overall rate of responding did not increase with discrimination training. On the other hand, the lesion group exhibited a considerable increase with training and, in addition, the rate rose with the number of preceding $\mathrm{S}-$ stimuli. Such transitional contrast effects have been reported for intact rate (e.g., Scull, Davies, \& Amsel, 1970). If anything, the lesion appeared to potentiate contrast effects in this experiment. Since septal damage also augments the baseline response rate, the change in contrast is confounded with the altered baseline rate. Dickinson (1973) found that when intact animals with equivalent baseline response rates were compared to the lesion group, there was no significant difference in the overall level of contrast. This is to be expected if the baseline rate and contrast both reflect the degree to which an animal is sensitive to the activating effects of frustrative nonreward. Septal damage and the selection of intact animals with high baseline rates may both produce groups with a high sensitivity.

Schedule-Induced Polydipsia. The high level of collateral drinking or schedule-induced polydipsia which results when a hungry animal is given small amounts of food intermittently has also been attributed to adjunctive or displacement behavior engendered by the frustrating nature of the food schedule (e.g., Panksepp, Toates, \& Oatley, 1972). Wayner and Greenberg's (1972) finding that septal damage increases schedule-induced polydipsia also points to an enhancement of the activating effects of frustrative nonreward. However, the increased schedule-induced polydipsia may simply be due to the general increase in water intake which follows large septal lesions (e.g., Harvey \& Hunt, 1965).

\section{Facilitating Effects of Mildly Aversive Stimuli}

In addition to the above examples using clearly aversive stimuli, septal enhancement of reactivity has been reported for what might well be regarded as mildly aversive auditory (Gotsick, 1969; Brown \& Remley, 1971), visual (Schwartzbaum et al, 1967; Donovick \& Wakeman, 1969; Brown \& Remley, 1971; Schwartzbaum, Kreinick, \& Levine, 1972; Schwartzbaum, Dilorenzo, Mello, \& Kreinick, 1972), and heat stimuli (Brown \& Remley, 1971).

In none of the cases considered has septal damage attenuated the facilitating effects of aversive stimuli and events in a manner that parallels its effects on their suppressive property. Except for the conditioned acceleration and the frustration effect, whose magnitudes were unaffected, the lesion actually increases the activating effects of shock, frustrative nonreward, 
and mildly aversive stimuli. Septal damage appears to dissociate the suppressive and facilitating properties of noxious stimuli by producing changes in opposite directions.

\section{DUAL NATURE OF AVERSIVE STIMULI}

Ever since Mowrer's (1947) classic two-factor theory of avoidance learning, the drive-enhancing effects of aversive stimuli have been regarded as one of their primary properties. However, the status of the capacity of aversive stimuli to suppress responding under certain contingencies has been far more contentious. Avoidance or escape theories of punishment (e.g., Mowrer, 1947, 1960; Dinsmoor, 1954; Solomon, 1964), by attributing response suppression under punishment to competition from avoidance or escape responses motivated by the drive properties of aversive stimuli, have regarded the suppressive effect as a derived or secondary property. However, if it is accepted that behavioral changes produced by septal lesions are relevant to normal functional organization, the pattern of dysfunction questions this hypothesis. The lesion-induced dissociation suggests that the two properties are mediated by separate functional systems which are relatively independent, and that septal damage disrupts the proper functioning of a suppression mechanism while leaving a facilitation mechanism operative.

Of course, this argument would be considerably strengthened if a double dissociation could be demonstrated by showing changes in the facilitative effects of aversive stimuli with minimal change in the suppressive capacity. Recent work by Henke and his collaborators provides such a demonstration. They have investigated the effects of amygdaloid lesions in a variety of situations supposedly sensitive to the energizing effects of frustrative nonreward. The results of these studies uniformly indicate a pattern of behavioral dysfunction directly opposed to that of septal damage-that is, a decrement in the energizing effects. Amygdaloid lesions attenuate the magnitude of the frustration effect in both the double runway (Henke \& Maxwell, 1973) and its free-operant analogues (Henke, 1973). Also, the lesion does not appear to augment response rates on fixed-ratio (Pellegrino, 1968) and variable-interval schedules (Henke, Allen, \& Davison, 1972) as does septal damage. Perhaps the most significant result though is the reduction in behavioral contrast in a successive go/no-go discrimination following lesions of the amygdala. Henke, Allen, and Davison (1972) found a complete absence of behavioral contrast following amygdaloid lesions even though operated and control rats suppressed responding in the nonrewarded stimulus to the same extent. Henke has also reported a comparable attenuation of contrast in mixed schedules (Henke, 1972) and in an extinction-reacquisition situation (Henke \& Bunnell,
1972) without a concurrent enhancement of nonreward persistence. The absence of nonreward persistence in successive go/no-go discriminations (see also Pellegrino, 1968) is particularly significant, for this is one of the tasks most sensitive to the persistence-enhancing effects of septal damage (Dickinson, 1973).

It appears that the activating effects of aversive stimuli can be attenuated without producing major changes in response persistence, a finding which gives further support to the idea that these two properties are mediated by relatively independent systems. However, it should be noted that as a summary of the effects of amygdaloid lesions, the above description is open to question from other evidence. For instance, Kemble and Tapp (1968) and Pellegrino (1968) have reported response persistence by rats in passive-avoidance tasks following amygdaloid damage. However, these tests used consummatory behavior as the punished response and the generality of the deficit has not yet been determined. In addition, the role of changes in species-specific defense reactions (Blanchard \& Blanchard, 1972) and of functional differentiation within the amygdala remains unclear. Generally, though, in the critical situations, septal and amygdaloid lesions do appear to produce contrasting patterns of behavioral response to aversive stimuli.

\section{INTERACTION BETWEEN SUPPRESSION AND FACILITATION MECHANISM}

If the response-facilitation and response-suppression mechanisms are completely independent, septal damage should have no effect on the energizing property of aversive stimuli. This does not appear to be so. In the case of positively correlated reward and punishment, behavioral contrast, and free-operant schedules, rats with septal damage respond at significantly higher rates than intact animals. Of course, the interaction between the two opposing response tendencies could occur at an overt behavioral level; septal lesions, by disrupting the suppression mechanisms, might permit the full expression of the underlying energizing effect on the measured behavior. Alternatively, the interaction might occur at a more fundamental level. Gray and Araujo-Silva (1971) have suggested that a septal response-suppression mechanism exerts an inhibitory influence on another independent system mediating the drive-enhancing effects of aversive stimuli. If this is so, septal damage should lead to a direct release of the energizing property of aversive stimuli.

\section{Septal-Amygdaloid Lesions and Inhibitory Interaction}

There is a limited amount of evidence to support the idea of a direct inhibitory interrelationship between some septal mechanism and a response-facilitation system associated with the amygdala. If a system associated with the septum exerts an inhibitory 
influence on the facilitation mechanism, disruption of this facilitation mechanism by amygdaloid damage should attenuate the heightened reactivity produced by septal lesions. In line with this prediction, King and Meyer (1958) (see also Jonason \& Enloe, 1971; Jonason, Enloe, Contrucci, \& Meyer, 1973) found that amygdaloid lesions decreased the septal hyperirritability syndrome (Brady \& Nauta, 1953). Although there might be some doubt as to whether the hyperirritability represents the same dysfunction as the facilitation found in shock and nonreward situations, the result is suggestive. Furthermore, if the interaction only affects facilitation, the addition of amygdaloid lesions should not alter the effects of septal damage on response persistence. Schwartzbaum and Gay (1966) have provided evidence for the selectivity of the interaction. While amygdaloid lesions reduce the general reactivity of septal preparations, nonreward persistence, as measured by the elevated response output in the initial segments of a fixed-interval schedule, is unaffected. Slotnick and McMullen (1973) also reported that the addition of amygdaloid lesions failed to attenuate the deficit in response suppression under shock resulting from septal lesions in mice.

\section{Generality of the Release from Inhibition}

On the basis of the evidence considered so far, a relatively gross model of the systems involved in the processing of aversive stimuli can be proposed. The model assumes that aversive stimuli are processed by two separate functional systems: a septum-associated response-suppression system and an amygdala-associated response-facilitation mechanism. Furthermore, it is suggested that some septal system exerts an inhibitory influence on the facilitation mechanism. There are good a priori reasons why such an inhibitory interaction should exist within the present model. It is obviously to the advantage of the animal to suppress responding under response-contingent aversive events, and full activation of the facilitation mechanism would work against such suppression without the inhibitory modulation. The implication of the present analysis is that the facilitation mechanism is only activated by stimuli of negative affective value. However, a number of authors have suggested that septal damage increases the motivating or reinforcing effects of a wide range of biologically significant stimuli of both positive and negative affective value. (e.g., Zucker, 1965; Beatty \& Schwartzbaum, 1968; Fallon \& Donovick, 1970; Carey, 1972; Caplan, 1973; Fried, 1973). Beatty and Schwartzbaum (1967) were the first to show that septal damage increased the intake of sucrose, and the enhanced activating effects of positive or incentive stimuli appears to be a quite general phenomenon. Anderson (1970), for instance, found that septal lesions increased the general activity elicited by a neutral stimulus paired with food delivery only when the rats were hungry. These and related findings suggest that the facilitation mechanism and the inhibitory modulation through a septal-associated mechanism are activated by a stimuli of both positive and negative affective value. As a result, it is probably best to consider the septum-associated mechanism mediating the inhibitory modulation of the response-facilitation system as functionally distinct from that controlling response suppression, the latter being only activated by negative-valued stimuli and events.

A schematic representation of the proposed functional mechanisms underlying the processing of aversive stimuli suggested by the behavioral effects of septal damage is outlined in Fig. 2. It is assumed that any stimulus input is initially evaluated for its affective quality and intensity. If these stimuli have significant affective value, whether positive or negative, they pass on to activate a general response-facilitation mechanism and a septal system involved in the inhibitory modulation of that mechanism. In addition, aversive stimuli selectively activate another pathway leading to a response-suppression system associated with the septum. This mechanism serves to decrease the emission of responses which precede the presentation of the aversive stimulus and responses occurring in the presence of the aversive stimulus which are based upon an appetitive motivational system. Whether the two septal mechanisms should be considered as anatomically and neurophysiologically discrete, as well as functionally independent, is yet unclear. Although a considerable number of studies compared the effects of small localized lesions within the septum (see Fried, 1973), consideration of this question is probably somewhat premature. In addition, the dissociation between the two systems may well be complicated by the fact that dysfunctions of both systems contribute to any given behavioral change following septal damage. For instance, Beatty et al (1973) have recently provided good evidence that both an increment in the effectiveness of positive incentives and a change in response suppression often contribute to response persistence under punishment.

Finally, it should be noted that the present theory is not intended to account for all the behavioral changes which result from septal damage. In view of the diverse anatomical connections of the septum and its differentiated structure, it is unlikely that this region subserves only a relatively simple functional system such as that outlined in the present paper.

\section{CONCLUSIONS}

It has been argued in the present paper that the patterns of behavioral breakdown seen after selective brain lesions are significant not only for determining the anatomical and neurophysiological systems representing the functional mechanisms underlying normal behavioral 


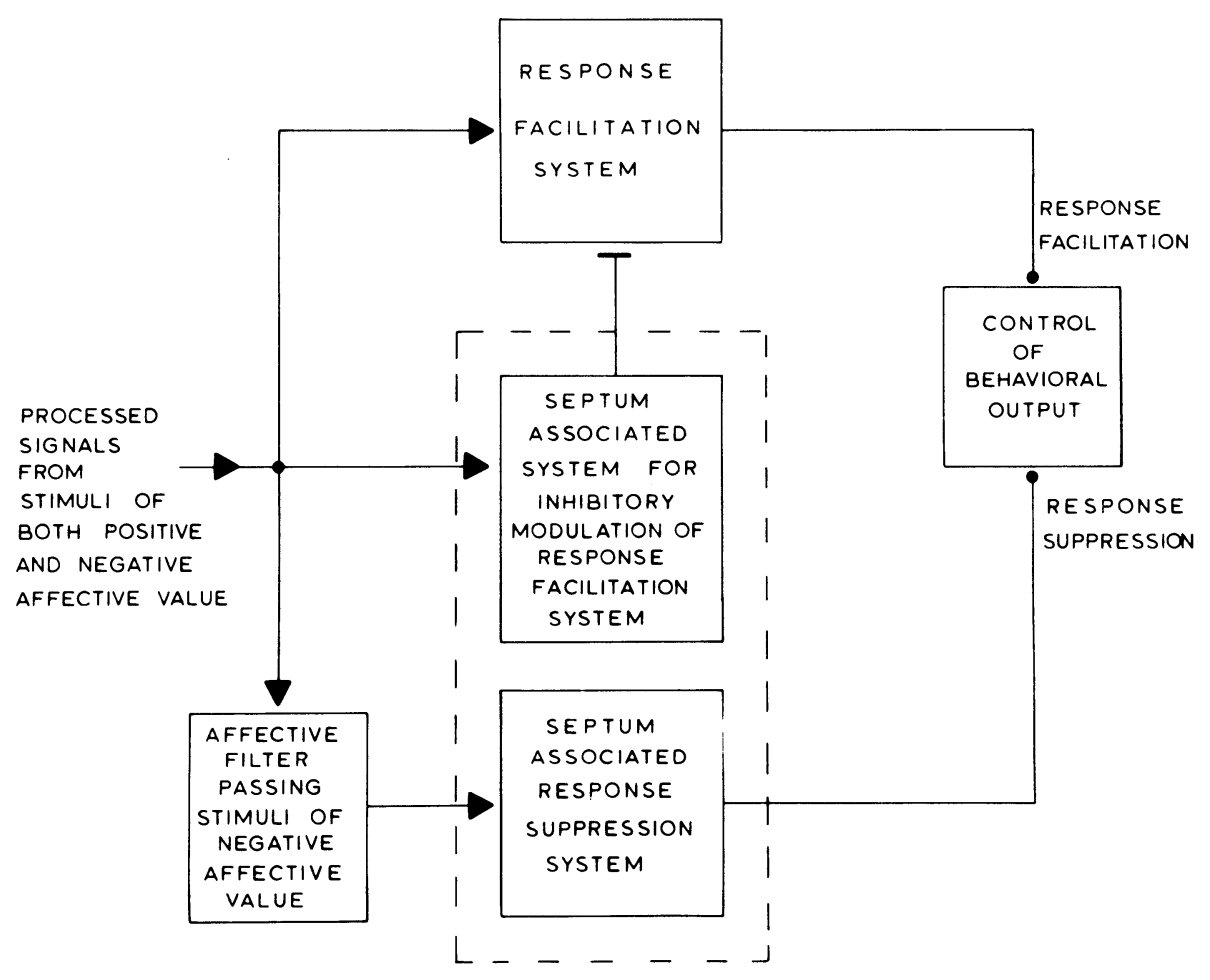

Fig. 2. A schematic model of the functional systems underlying the processing of aversive stimuli in punishment and nonreward situations. Large septal lesions are assumed to lead to an increase in response persistence both by the disruption of a response suppression system and a system exerting inhibitory modulation over a response facilitation system associated with the amygdala. The addition of amygdaloid lesions removes the effect of septal damage on the underlying response facilitation but not response suppression.

adjustment, but also in understanding the nature and organization of these functional mechanisms themselves. In fact, an account of such mechanisms is a necessary prerequisite to formulating structure-function relationships (Luria, 1973), and an important role must be played by theoretical concepts developed in normal behavior theory in explaining the effects of neurophysiological disruption. In turn, lesion-induced dysfunctions provide a valuable adjunct to the effects of normal behavioral manipulations in the assessment of these concepts. This is particularly true in cases where response tendencies are determined by two opposing functional mechanisms whose effect is to mask each other in normal overt behavior.

The behavioral changes which follow septal damage would seem to be particularly useful in analyzing the mechanisms involved in processing aversive stimuli. The selective effects of septal damage in rats on shock and nonreward persistence are not adequately accounted for either in terms of a deficit in the association of response-dependent cues with aversive stimuli or by an attenuation of the effective aversiveness of the stimuli. Rather, the dysfunctions point to a theory in which the drive-enhancing or activating properties of aversive stimuli are processed by a system which can be differentiated from that mediating the suppressive effects of such stimuli. As a consequence, the septal preparation provides difficulties for accounts of punishment and extinction which explain response decrements in terms of the development of competing responses based primarily on the motivational properties of shock and nonreward. The concept of a specific response-inhibition mechanism seems to be necessary if a complete account of punishment and extinction is to be given.

\section{REFERENCES}

Ahnad, S. S., \& Harvey, J. A. Long-term effects of septal lesions and social experience on shock-elicited fighting in rats. Journal of Comparative \& Physiological Psychology, 1968, 66, 596-602.

Ain, B. R., Lubar, J. F., Moon, R. D., \& Kulig, B. M. Effect of septal and neocortical damage on complex maze learning. Physiology \& Behavior, 1969, 4, 235-238.

Amsel, A. The role of frustrative nonreward in noncontinuous reward situations. Psychological Bulletin, 1958, 55, 102-119.

Amsel, A. Frustrative nonreward in partial reinforcement and discrimination learning: Some recent history and a theorectical extension. Psychological Review, 1962, 69, 306-328.

Amsel, A. Positive induction, behavioral contrast, and generalization of inhibition in discrimination learning. In $\mathbf{H}$. H. Kendler and J. T. Spence (Eds.), Essays in neobehaviorism: $A$ memorial volume to Kenneth $W$. Spence. New York: Appleton-Century-Crofts, 1971. Pp. 217-236.

Amsel, A., \& R oussel, J. Motivational properties of frustration: I. Effect on a running response of the addition of frustration to the motivational complex. Journal of Experimental Psychology, 1952, 43, 363-368.

Anderson, R. A. Appetitively motivated general activity in rats with limbic lesions. Physiology \& Behavior, 1970, 5, 755-761.

Appel, J. B. Association of aversive and reinforcing stimuli during intermittent punishm ent. Psychological R eports, 1968, 22, 267-271.

Beatty, W. W., \& Schwartzbaum, J. S. Enhanced reactivity to quinine and saccharine solutions following septal lesions in the rat. Psychonomic Science, 1967, 8, 483-484.

Beatty, W. W., \& Schwartzbaum, J. S. Consummatory behavior for sucrose following septal lesions in the rat. Journal of Comparative \& Physiological Psychology, 1968, 65, 93-102. Beatty, W. W., Beatty, P. A., O'Briant, D. A., Gregoire, K. C., \& Dahi, B. L. Factors underlying deficient passive-avoidance by rats with septal lesions. Journal of Comparative \& Physiological Psychology, 1973, 85, 502-514.

Besch, M. F., \& Van Dyne, G. C. Effects of locus and size of 
septal lesions on consummatory behavior in the rat. Physiology \& Behavior, 1969, 4, 953-958.

Blanchard, D. C., \& Blanchard, R. J. Innate and conditioned reactions to threat in rats with amygdaloid lesions. Journal of Comparative \& Physiological Psychology, 1972, 81, 281-290.

Blanchard, R. J., \& Blanchard, D. C. Limbic lesions and reflexive fighting. Journal of Comparative \& Physiological Psychology. $1968,66,603-605$.

Blanchard, R. J., \& Fial, R. A. Effects of limbic lesions on passive avoidance and reactivity to shock. Journal of Comparative \& Physiological Psychology, 1968, 66, 606-612

Bloom field, T. M. Frustration, preference, and behavioural contrast. Quarterly Journal of Experimental Psychology, 1967, 19, 166-169.

Bolles, R. C., \& Warren, J. A. The acquisition of bar press avoidance as a function of shock intensity. Psychonomic Science, 1965, 3, 297-298.

Brady, J. V., \& Nauta, W. J. H. Subcortical mechanisms in emotional behavior: Affective changes following septal forebrain lesions in albino rats. Journal of Comparative \& Physiological Psychology, 1953, 46, 339-346.

Brown, G. E., \& Remley, N. R. The effects of septal and olfactory bulb lesions on stimulus reactivity. Physiology \& Behavior, 1971, 6, 497-501.

Brown, J. S., Kalish, H. I., \& Farber, I. E. Conditioned fear as revealed by magnitude of startle response to an auditory stimulus. Journal of Experimental Psychology, 1951, 41, 317-328.

Camp, D. S., Raymond, G. A., \& Church, R. M. Temporal relationship between response and punishment. Journal of Experim ental Psychology, 1967, 74, 114-123.

Caplan, M. An analysis of the effects of septal lesions on negatively reinforced behavior. Behavioral Biology, 1973, 9, 129-167.

Caplan, M., \& Stamm, J. DRL acquisition in rats with septal lesions. Psychonomic Science, 1967, 8, 56.

Carey, R. J. Contrasting effects of anterior and posterior septal injury on thirst motivated behavior. Physiology \& Behavior, $1969,4,759-764$.

Carey, R. J. A neuroanatomical investigation of enhanced cutaneous gustatory responsivity associated with septal forebrain injury. Journal of Comparative \& Physiological Psychology, $1972,80,449-457$.

Carlson, N. R., \& Cole, J. R. Enhanced alternation performance following septal lesions in mice. Journal of Comparative \& Physiological Psychology, 1970, 73, 157-161.

Church, $R$. M. The varied effects of punishment on behavior. Psychological R eview, 1963, 70, 369-402.

Dalby, D. A. Effects of septal lesions on the acquisition of two types of active avoidance behavior in rats. Journal of Comparative \& Physiological Psychology, 1970, 73, 278-283.

D'Amato, M. R., \& Fazzaro, J. Discriminated lever-press avoidance learning as a function of type and intensity of shock. Journal of Comparative \& Physiological Psychology, 1966, 61, 313-315.

D'Amato, M. R., Fazzaro, J., \& Etkin, M. Discriminated bar-press avoidance maintenance and extinction in rats as a function of shock intensity. Journal of Comparative \& Physiological Psychology, 1967, 63, 351-354.

Deagle, J. H., \& Lubar, J. F. Effects of septal lesions in two strains of rats on one-way and shuttle avoidance acquisition. Journal of Comparative \& Physiological Psychology, 1971, 77 , 277-281.

Dickinson, A. Septal damage and response output under frustrative nonreward. In R. A. Boakes and M. S. Halliday, Inhibition and learning. London: Academic Press, 1972a. Pp. 461-496.

Dickinson, A. Disruption of free-operant successive discriminations by septal damage in rats. Quarterly Journal of Experim ental Psychology, 1972b, 24, 524-535.

Dickinson, A. Septal lesions in rats and the acquisition of free-operant successive discriminations. Physiology \& Behavior, 1973, 10, 305-313.

Dickinson, A. Suppressive and enhancing effects of footshock on food-reinforced operant responding following septal lesions in rats. Journal of Comparative \& Physiological Psychology, 1974 in press.

Dickinson, A., \& Morris, R. G. M. Conditioned acceleration and free-operant wheel-turn avoidance following septal lesions in rats. Physiological Psychology, 1975, in press.

Dinsmoor, J. A. Punishment: I. The avoidance hypothesis. Psychological R eview, 1954, 61, 34-46.

Donovick, P. J., Burright, R. G., \& Gittleson, P. L. Bodyweight and food and water consumption in septal lesioned and operated control rats. Psychological Reports, 1969, 25, 303-310.

Donovick, P. J., \& Wakeman, K. A. Open-field luminance and 'septal hyperemotionality'. Animal Behavior, 1969, 17, 186-190.
Duncan, P. M., \& Duncan, N. C. Free-operant and T-maze avoidance by septal and hippocampal-damaged rats. Physiology \& Behavior, 1971, 7, 687-693.

Dunham, P. J. Punishment: Method and theory. Psychological R eview, 1971, 78, 58-70.

Eichelman, B. S. Effects of subcortical lesions on shock-induced aggression in the rat. Journal of Comparative \& Physiological Psychology, 1971, 74, 331-339.

Ellen, P., \& Powell, E. W. Temporal discrimination in rats with rhinencephalic lesions. Experimental Neurology, 1962, 6 , 538-547.

Ellen, P., Wilson, A. S., \& Powell, E. W. Septal inhibition and timing behavior in the rat. Experimental Neurology, 1964, 10, 120-132.

Ellen, P., \& Butter, G. External cue control of DRL performance in rats with septal lesions. Physiology \& Behavior, 1969, 4 , 1-6.

Ellen, P., Kelnhoffer, M. Discrimination of response feedback following septal lesions. Psychonomic Science, 1971, 23, 94-96.

Estes, W. K. Outline of a theory of punishment. In B. A Campbell and R. M. Church, Punishment and aversive behavior. New York: Appleton-Century-Crofts, 1969. Pp. 57-82.

Fallon, D., \& Donovick, P. J. Low resistance to extinction in rats with septal lesions under inappropriate appetitive motivation Journal of Comparative \& Physiological Psychology, 1970, 73, 150-156.

Frank, L. H., \& Beatty, W. W. Effects of septal lesions on passive avoidance behavior using ice water as the aversive stimulus. Physiology \& Behavior, 1974, 12, 321-323.

Freedman, P. E., Hennessy, J. W., \& Groner, D. Effects of varying active/passive shock levels in shuttle box avoidance in rats. Journal of Comparative \& Physiological Psychology, $1974,86,79-84$.

Freeman, B. H. Behavioral contrast: R einforcement frequency or response suppression. Psychological Bulletin, 1971, 75 , 347-356.

Fried, P. A. The septum and behavior: A review. Psychological Bulletin, 1973, 78, 292-310.

Garber, E. E., \& Simmons, H. J. Facilitation of two-way avoidance performance by septal lesions in rats. Journal of Comparative \& Physiological Psychology, 1968, 66, 559-562.

Gerbrandt, L. K. Neural systems of response release and control Psychological Bulletin, 1965, 64, 113-123.

Gittleson, P. L., \& Donovick, P. J. The effect of septal lesions on learning and reversal of a kinesthetic discrimination. Psychonomic Science, 1968, 13, 137-138.

Gittleson, P. L., Donovick, P. J., \& Burright, R. G. F acilitation of passive avoidance acquisition in rats with septal lesions. Psychonomic Science, 1969, 17, 292-293.

Goodrich, $K$. P. Performance in different segments of an instrumental response chain as a function of reinforcement schedule. Journal of Experimental Psychology, 1959, 57, 57-63.

Gotsick, J. E. Factors affecting spontaneous activity in rats with limbic lesions. Physiology \& Behavior, 1969, 4, 587-593.

Gotsick, J. E., Osborne, F. H., Allen, C. J., \& Hines, K. M. Factors affecting performance on a shock escape task in rats with septal lesions. Physiology \& Behavior, 1971, 6, 199-202.

Gray, J. A. Sodium amobarbital, the hippocampal the ta rhythm and the partial reinforcement extinction effect. Psychological $R$ eview, 1970, 77, 465-480.

Gray, J. A., \& Araujo-Silva, M. T. Joint effects of medial septal lesions and amylobarbitone injections on resistance to extinction in the rat. Psychopharmacologia (Berlin), 1971, 22 8-22.

Gray, J. A., Quintao, L., \& Araujo-Silva, M. T. The partial reinforcement extinction effect in rats with medial septal lesions. Physiology \& Behavior, 1972, 8, 491496.

Hamilton, L. W. Intrabox and extrabox cues in avoidance responding: Effect of septal lesions. Journal of Comparative \& Physiological Psychology, 1972, 78, 268-273.

Harvey, J. A., \& Hunt, H. F. Effects of septal lesions in rats on thirst as indicated by water consumption and operant responding for water reward. Journal of Comparative \& Physiological Psychology, 1965, 59, 49-56.

Harvey, J. A., Lints, C. E., Jacobson, L. E., \& Hunt, H. F. Effects of lesions in the septal area on conditioned fear and discriminated instrumental punishment in the albino rat. Journal of Comparative \& Physiological Psychology, 1965, 59, 37-48.

Henke, P. G. Amygdalectomy and mixed reinforcement schedule contrast effects. Psychonomic Science, 1972, 28, 301-302.

Henke, P. G. Effects of reinforcement omission on rats with lesions in the amygdala. Journal of Comparative \& Physiological Psychology, 1973, 84, 187-193.

Henke, P. G. Persistence of runway performance after septal lesions in rats. Journal of Comparative \& Physiological 
Psychology, 1974, 86, 706-767.

Henke, P. G., Allen, J. D., \& Davison, C. Effect of lesions in the amygdala on behavioral contrast. Physiology \& Behavior, 1972, 8, 173-176.

Henke, P. G., \& Bunnell, B. N. R einforcement and extinction interactions after limbic lesions in rats. Communications in Behavioral Biology, 1972, 6, 329-333.

Henke, P. G., \& Maxwell, D. Lesions in the amygdala and the frustration effect. Physiology \& Behavior, 1973, 10,647-650.

Hothersall, D. Johnson, D. A., \& Collen, A. Fixed-ratio responding following septal lesions in the rat. Journal of Comparative \& Physiological Psychology, 1970, 73, 470-476.

Jonason, K. R., \& Enloe, L. J. Alterations in social behavior following septal and amygdaloid lesions in the rat. Journal of Comparative \& Physiological Psychology, 1971, 75, 286-301.

Jonason, K. R., Enloe, L. J., Contrucci, J., \& Meyer, P. A. Effects of simultaneous and successive septal and amygdaloid lesions on social behavior of the rat. Journal of Comparative \& Physiological Psychology, 1973, 83, 54-61.

Kaada, B. R. Rasmussen, E. W., \& Kveim, O. Impaired acquisition of passive avoidance behavior by subcallosal septal, hypothalamic and insular lesions in rats. Journal of Comparative \& Physiological Psychology, 1962, 55, 661-670.

Kasper-Pandi, P., Schoel, W. H., \& Zysman, M. Motivation and response strength in passive avoidance deficits of septal lesioned rats. Physiology \& Behavior, 1969, 4, 815-821.

Kemble, E. D., \& Tapp, J. T. Passive and active avoidance following small amygdaloid lesions in rats. Physiology \& Behavior, 1968, 3, 713-718.

Kenyon, J., \& Kreickhaus, E. E. Decrements in one-way avoidance learning following septal lesions in rats. Psychonomic Science, 1965, 3, 113-114.

King, F. A. Effects of septal and amygdaloid lesions on emotional behavior and conditioned avoidance responses in the rat. Journal of Nervous \& Mental Disease, 1958, 126 , 57-63.

King, F. A., \& Meyer, P. M. Effects of amygdaloid lesions upon septal hyperemotionality in the rat. Science, 1958, 128, 655-656.

Kriekhaus, E. E., Simmons, H. J., Thomas, G. J., \& Kenyon, J. Septal lesions enhance shock avoidance in the rat. Experimental Neurology, 1964, 9, 107-113.

Koppell, S., \& Sodetz, F. J. Septal ablation in the rat and bar pressing under appetitive and aversive control. Journal of Comparative \& Physiological Psychology, 1972, 81, 274-280.

LaVaque, I. J. Conditioned avoidance response perseveration in septal rats during massed extinction trials. Psychonomic Science, 1966, 5, 409-410.

Lints, C. E., \& Harvey, J. A. Altered sensitivity to foot shock and decreased brain content of serotonin following brain lesions in the rat. Journal of Comparative \& Physiological Psychology, 1969, 67, 23-31.

Lorens, S. A., \& Kondo, C. Y. Effects of septal lesions on food and water intake and operant responding for food. Physiology \& Behavior, 1969, 4, 729-732.

Lubar, J. F., Schaeffer, C. F., \& Wells, D. G. The role of the septal area in the regulation of water intake and associated motivational behavior. Annals of the New York Academy of Sciences, 1969, 157, 875-893.

Lubar, J. F., Brener, J. M., Deagle, J. H., Numan, R., \& Clemens, W. J. Effect of septal lesions on detection threshold and unconditional response to shock. Physiology \& Behavior, $1970,5,459-463$.

Lubar, J. F., \& Numan, R. Behavioral and physiological studies of septal function and related medial cortical structures. Behavioral Biology, 1973, 8, 1-25.

Lubar, J. F., Herrmann, T. F., Moore, D. R., \& Shouse, M. N. Effect of septal and frontal ablations on species-typical behavior in the rat. Journal of Comparative \& Physiological Psychology, 1973, 83, 260-270.

Luria, A. R. The working brain: An introduction to neuropsychology. London: Allen Lane, 1973.

Mabry, P. D., \& Peeler, D. F. Effects of septal lesions on response to frustrative nonreward. Physiology \& . Behavior, 1972, 8, 909-913.

Martin, L. K., \& Riess, D. Effects of US intensity during previous discrete delay conditioning on conditioned acceleration during avoidance extinction. Journal of Comparative \& $\mathrm{Ph}$ ysiological Psychology, 1969, 69, 196-200.

McAllister, W. R., McAllister, D. E., \& Douglas, W. K. The inverse relationship between shock intensity and shuttle-box avoidance learning in rats: A reinforcement explanation. Journal of Comparative \& Physiological Psychology, 1971, 74, 426-433.

McCleary, R. A. Response-modulating functions of the limbic system: Initiation and suppression. In E. Stellar and J. M. Sprague (Eds.), Progress in physiological psychology, Vol. 1. New York: A cademic Press, 1966. Pp. 209-272.

McNew, J. J., \& Thompson, R. Role of the limbic system in active and passive avoidance conditioning in the rat. Journal of Comparative \& Physiological Psychology, 1966, 61, 173-180.

Miczek, K. A., Kelsey, J. E., \& Grossman, S. P. Time course of effects of septal lesions on avoidance, response suppression, and reactivity to shock. Journal of Comparative \& Physiological Psychology, 1972, 79, 318-327.

Morgan, J. M., \& Mitchell, J. C. Septal lesions enhance delay of responding on a free-operant avoidance schedule. Psychomic Science, 1969, 16, 10-11.

Mowrer, $O$. $H$. On the dual nature of learning-A re-interpretation of "conditioning" and "problem-solving." Harvard Educational R eview, 1947, 17, 102-148.

Mowrer, O. H. Learning theory and behavior. New York: Wiley, 1960 .

Moyer, K. E., \& Korn, J. H. Effect of UCS intensity on the acquisition and extinction of an avoidance response. Journal of Experimental Psychology, 1964, 67, 352-359.

Murray, M., \& Nevin, J. A. Some effects of correlation between response-contingent shock and reinforcement. Journal of the Experimental A nalysis of Behavior, 1967, 10, 301-309.

Panksepp, J., Toates, F. M., \& Oatley, K. Extinction induced drinking in hungry rats. Animal Behavinur, 1972, 20, 493-498.

Pellegrino, L. Amygdaloid lesions and behavioral inhibition in the rat. Journal of Comparative \& Physiological Psychology, $1968,65,483-491$

Powell, R. W. The effect of shock intensity upon responding und er a multipleavoidance schedule. Journal of the Experimental Analysis of Behavior, 1970, 14, 321-329.

Rachlin, H. \& Herrnstein, R. J. Hedonism revisited: On the negative law of effect. In B. A. Campbell and R. M. Church (Eds.), Punishment and aversive behavior. New York: Appleton-Century-Crofts, 1969. Pp. 83-110.

Raphelson, A. C., Isaacson, R. L., \& Douglas, R. J. The effect of limbic damage on the retention and performance of a runway response. Neuropsychologia, 1966, 4, 243-264.

Rescorla, R. A., \& Solomon, R. L. Two process learning theory: Relationship between Pavlovian conditioning and instrumental learning. Psychological R eview, 1967, 74, 151-182.

Riess, D. Sidman avoidance in rats as a function of shock intensity and duration. Journal of Comparative \& Physiological Psychology, 1970, 73, 481-485.

Riess, D., \& Farrar, C. H. Shock intensity, shock duration, Sidman avoidance acquisition, and the "all or nothing" principle in rats. Journal of Comparative \& Physiological Psychology, 1972, 81, 347-355.

Riess, D., \& F arrar, C. H. US duration, conditioned acceleration, multiple $C R$ measurement, and Pavlovian $R-R$ laws in rats. Journal of Comparative \& Physiological Psychology, 1973, 82, 144-151.

Rilling, M. E., Askew, H. R., Ahlskog, J. E., \& Kramer, T. J. Aversive properties of the negative stimulus in a successive discrimination. Journal of Experimental Analysis of Behavior, $1969,12,917-932$

Schnelle, J. F., Walker, S. F., \& Hurwitz, H. M. B. Concurrent performance in septally operated rats: One and two response extinction. Physiology \& Behavior, 1971, 6, 649-654.

Schwartzbaum, J. S., \& Spieth, T. M. Analysis of the response inhibition concept of septal function in passive avoidance behavior. Psy chonomic Science, 1964, 1, 145-146.

Schwartzbaum, J. S., Kellicut, M. H., Spieth, T. M., \& Thompson, J. B. Ef fects of septal lesions in rats on response inhibition associated with food reinforced behavior. Journal of Comparative \& Physiological Psychology, 1964, 58, 217-224.

Schwartzbaum, J. S., \& Gay, P. E. Interacting effects of septal and amygdaloid lesions in the rat. Journal of Comparative \& Physiological Psychology, 1966, 61, 59-65.

Schwartzbaum, J. S., Green, R. H., Beatty, W. W., \& Thompson J. B. Acquisition of avoidance behavior following septal lesions in the rat. Journal of Comparative \& Physiological Psychology, 1967, 63, 95-104.

Schwartzbaum, J. S., \& Donovick, P. J. Discrimination reversal and spatial alternation associated with septal and caudate dysfunction in rats. Journal of Comparative \& Physiological Psychology, 1968, 65, 83-92.

Schwartzbaum, J. S., Kreinick, C. J., \& Levine, M. S. Behavioral reactivity and visual evoked potentials to photic stimuli following septal lesions in rats. Journal of Comparative \& Physiological Psychology, 1972, 80, 123-142.

Schwartzb aum, J. S., Dilorenzo, P. M., Mello, W. F., \& Kreinick C. J. Further evidence of dissociation between reactivity and visual evoked response following septal lesions in rats. Journal of Comparative \& Physiological Psychology, 1972, 80, 143-149.

Schwartzbaum, J. S., \& Kreinick, C. J. Visual evoked potentials during appetitive behavior after septal lesions in rats. Journal of Comparative \& Physiological Psychology, 1974, 86, 
509-522.

Scobie, S. R. Interactions of an aversive Pavlovian conditional stimulus with aversively and appetitively motivated operants in rats. Journal of Comparative \& Physiological Psychology, 1972, 79, 171-188.

Scull, J., Davies, K., \& Amsel, A. Behavioral contrast and frustration effect in multiple and mixed fixed-interval schedules in the rat. Journal of Comparative \& Physiological Psychology, 1970, 71, 478-483.

Slotnick, B. M. Disturbances of maternal behaviour in the rat following lesions of the cingulate cortex. Behaviour, 1967, 29 , 204-236.

Slotnick, B. M., \& McMullen, M. F. R esponse inhibition deficits in mice with septal, amygdala, or cingulate cortical lesions. Physiology \& Behavior, 1973, 10, 385-389.

Sodetz, F. J. Septal ablations and free-operant avoidance behavior in the rat. Physiology \& Behavior, 1970, 5, 773-7 77.

Sodetz, F. J. Sidman avoidance performance and response suppression in rats with septal lesions. Journal of Comparative \& Physiological Psychology, 1972, 79, 142-150.

Solomon, R. L. Punishment. American Psychologist, 1964, 19 , 239-253.

Spence, K. W. The nature of discrimination learning in animals. Psychological R eview, 1936, 43, 427-449.

Stahl, J. M., \& Ellen, P. Septal lesions and reasoning performance in the rat. Journal of Comparative \& Physiological Psychology, 1973, 84, 629-638.

Theios, J., Lynch, A. D., \& Lowe, W. Differential effects of shock intensity on one-way and shuttle avoidance conditioning. Journal of Experimental Psychology, 1966, 72, 294-299.

Thomas, G. J., Moore, R. Y., Harvey, J. A., \& Hunt, H. F. Relations between the behavioral syndrome produced by lesions in the septal region of the forebrain and maze learning of the rat. Journal of Comparative \& Physiological Psychology, 1959, 52, 527-532.

Thomas, G. J., Hostetter, G., \& Barker, D. J. Behavioral functions of the limbic system. In E. Stellar and J. M. Sprague (Eds.), Progress in physiological psychology. Vol. 2. New York: Acad emic Press, 1968. Pp. 229-311.

Thomas, J. B. Non-appetitive passive avoidance in rats with septal lesions. Physiology \& Behavior, 1972, 8, 1087-1092.

Thomas, J. B., \& Van Atta, L. Hyperirritability, lever-press avoidance, and septal lesions in the albino rat. Physiology \& Behavior, 1972, 8, 225-232.

Ursin, H., Linck, P., \& McCleary, R. A. Spatial differentiation of avoidance deficit following septal and cingulate lesions. Journal of Comparative \& Physiological Psychology, 1969, 68, 103-113.

Vanderwolf, C. H. Effects of combined medial thalamic and septal lesions in active avoidance behavior. Journal of Comparative \& Physiological Psy chology, 1964, 58, 31-37.

Van Hoesen. G. W., MacDougall, J. M., \& Mitchell, J. C.
Anatomical specificity of septal projections in active and passive avoidance behavior in rats. Journal of Comparative \& Physiological Psychology, 1969, 68, 80-89.

Van Hoesen, G. W., MacDougall, J. M., \& Mitchell, J. C. Discrimination of emitted behavior following septal area lesions in rats. Journal of Comparative \& Physiological Psychology, 1972, 80, 106-122.

Wagner, A. R. Frustrative nonreward: A variety of punishment? In B. A. Campbell and R. M. Church (Eds.), Punishment and aversive behavior. New York: Appleton-Century-Crofts, 1969. Pp. 157-181.

Wayner, M. J., \& Greenberg, I. Effects of septal lesions on palatability modulation of schedule-induced polydipsia. Physiology \& Behavior, 1972, 9, 663-665.

Wetzel, A. B., Conner, R. L., \& Levine, S. Shock-induced fighting in septal-lesioned rats. Psychonomic Science, 1967, 9 133-134.

Williams, D. R., \& Barry, H. III Counter conditioning in an operant conflict situation. Journal of Comparative \& Physiological Psychology, 1966, 61, 154-156.

Winocur, G., \& Mills, J. A. Hippocampus and septum in response inhibition. Journal of Comparative \& Physiological Psychology, 1969, 3, 352-357.

Wishart, T. B., \& Mogenson, G. J. Effects of food deprivation on water intake in rats with septal lesions. Physiology \& Behavior, 1970, 5, 1481-1486.

Zucker, I. Effect of lesions of the septal-limbic area on behavior of cats. Journal of Comparative \& Physiological Psychology $1965,60,344-352$

\section{NOTE}

1. Reports by LaVaque (1966) and Van Hoesen, MacDougall, and Mitchell (1969) of prolonged responding during extinction of a two-way active avoidance response following septal damage would seem to be at variance with this generalization. Unfortunately, these studies used a massed extinction procedure in which the intertrial interval during extinction was shorter than during acquisition. Van Hoesen et al (1969) reported that the brain-damaged rats made more intertrial interval responses during acquisition which were not punished in either study. Massing the extinction trials would allow certain responses that would be regarded as intertrial interval responses during acquisition to be registered as avoidance responses during extinction, and it may be that the different extinction scores reflected different levels of intertrial responding even though the lesion and control groups were trained to the same acquisition criterion.

(Received for publication June 27, 1974; accepted July $16,1974$. 